\title{
Perforated duodenal ulcer in Reading from 1950 to 1959
}

\author{
PAUL CASSELL
}

From the Royal Berkshire Hospital, Reading

During the last 15 years there has been an evolution in the management of perforated peptic ulcer. The established policy of immediate laparotomy and simple closure of the lesion has been challenged by those advocating either non-operative conservatism (Taylor and Warren, 1956) or, at the other extreme, emergency definitive surgery (Judin, 1937; Cooley, Jordan, Brockman, and DeBakey, 1955; Emmett and Williams, 1957).

The purpose of this study was to assess the influence of these changing concepts of treatment upon the surgical practice in a busy district hospital. In addition, a long-term follow up was carried out with particular reference to the number of patients managed by simple closure coming eventually to definitive surgery. Subsidiary investigations were made into the natural history of those patients sustaining a second perforation. A further study into the relationship of the duration of dyspepsia before perforation and the subsequent course of the ulcer is reported elsewhere (Cassell, 1969).

The records of 330 patients admitted with perforated duodenal ulcers to the Royal Berkshire Hospital, Reading, between January 1950 and December 1959 were reviewed, and all those treated operatively were followed up. Five of them sustained a second perforation during the 10 years, and therefore this report surveys the management of 335 perforations occurring in 330 patients.

\section{DESCRIPTION OF PATIENTS}

ANNUAL ADMISSIONS The number of patients admitted each year is outlined in Fig. 1 , and will be seen to vary between 21 and 46, the average being 33.5. When the rapid increase of population in the area of intake is taken into account, there appears to be a small decrease in the incidence of the emergency. Probably one reason for this is the greater readiness with which patients are referred for, and offered, elective surgery now.

During this same period, 29 patients were admitted for perforated gastric ulceration. Their numbers

Present address: St Bartholomew's Hospital, London.

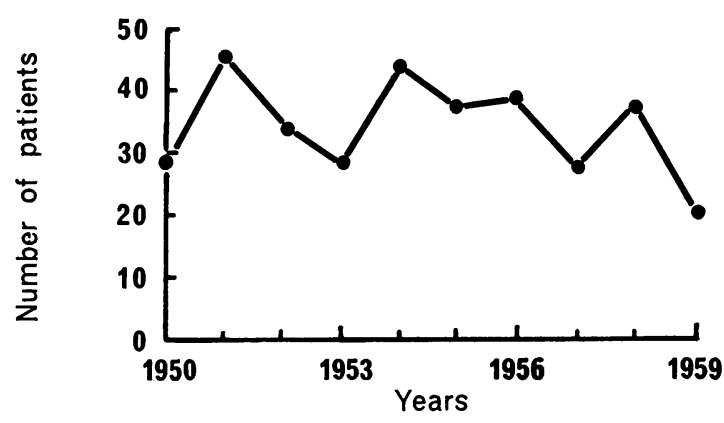

FIG. 1. Number of patients admitted during the survey period.

each year were too small to assess whether a similar decline was evident amongst them. The overall ratio was 1 to 12 of gastric ulcer to duodenal ulcer, which is higher than that found in a recent report from an adjacent area (Sanders, 1967), but markedly lower than that reported from other centres

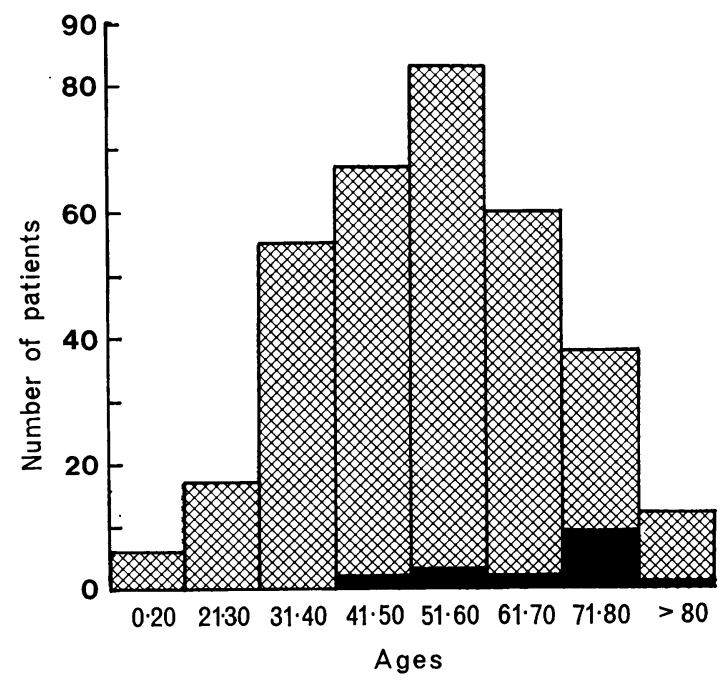

FIG. 2. Age distribution and mortality rate. 
(Illingworth, Scott, and Jamieson, 1944); Weir, 1960).

AGE The age distribution of patients presenting with perforated duodenal ulcer is illustrated in Figure 2. The peak age group was 51 to 60 , with the preceding and succeeding decades next. These findings are similar to those of other recent series (Sanders, 1967) although perforations appear to be occurring more often in patients over 60 . This latter fact is probably due to the greater number of elderly people in the community.

SEX The male to female ratio of 6.25 to 1 ( 269 men, 43 women) reflects the trend over the last 50 years. The Glasgow series then gave a ratio of more than 20 to 1 (Illingworth et al, 1944) while the latest reports approximate closely to our own findings (Mackay, 1966; Sanders, 1967).

\section{MANAGEMENT}

All patients admitted with perforated peptic ulcer were managed by immediate operation unless it was considered that their condition would have rendered its outcome almost certainly fatal. Twenty-three $(6.9 \%)$ patients came within the latter category and were treated by conservative measures, although two of them died even before these could be implemented. It is obvious that this small group of patients could not be considered subjects for a fair trial of conservative management of perforated ulcer.

The remaining $312(93.1 \%)$ patients who were treated surgically had either a simple closure, simple closure together with gastrojejunostomy, or partial gastrectomy (Table I). Two hundred and forty-one

TABLE I

ANALYSIS OF MANAGEMENT OF PATIENTS

\begin{tabular}{lcr} 
Mode of Treatment & $\begin{array}{l}\text { Number of } \\
\text { Patients }\end{array}$ & Percentage \\
\hline Simple closure only & 241 & 71.9 \\
Simple closure and gastrojejunostomy & 19 & $5 \cdot 7$ \\
Partial gastrectomy & 52 & $15 \cdot 5$ \\
Not operated & 23 & 6.9
\end{tabular}

$(71.9 \%)$ patients had simple closure alone, $19(5.7 \%)$ had simple closure and gastrojejunostomy, and 52 $(15.5 \%)$ partial gastrectomy. The trend over the 10-year period towards immediate definitive surgery is seen by reference to Figure 3. There was no emergency gastrectomy in 1950 and only one in 1951. During the next five years, with the exception of 1953, approximately one patient in every eight or nine had partial gastrectomy. In the last three years of the series the number rose to one in three.

The addition of gastrojejunostomy in some

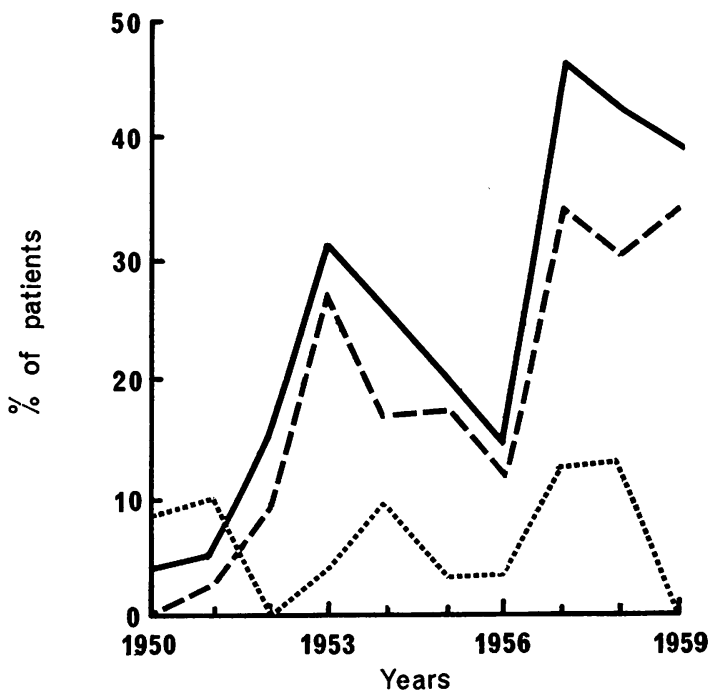

FIG. 3. Evolution of management and operative mortality rate. - gastroenterostomy; - - partial gastrectomy; . . . . operative mortality rate.

patients with simple closure of the perforation was confined to those above 50 years of age, 11 of the 19 being over 70 . The indications for its use were in the elderly or to bypass a pyloric obstruction due either to extensive scarring or oedema, in those unfit for gastrectomy.

During the years under review, the definitive operation employed in Reading was usually a Polya gastrectomy, although six patients had a Billroth I operation. It should be added that after 1959, vagotomy and pyloroplasty became the operation of choice for duodenal ulcer, and that patients coming to surgery after this date were treated in this way.

\section{FOLLOW UP}

Every effort was made to follow up each patient. Some were attending clinics in the hospitals of the area and up-to-date information was obtained from their records. Others were contacted by letter and, if any problems appeared to require examination, were asked to attend the outpatient department. A few patients, either elderly or living at a distance, were followed up by reference to their practitioners. The important aspect of the investigation was to establish whether further complications had occurred and operations elsewhere had become necessary.

The analysis of the follow up is shown in Figure 4. Two hundred and twenty-eight of the original 290 patients were followed up for at least five years, representing $78.6 \%$ of the operative survivors. 


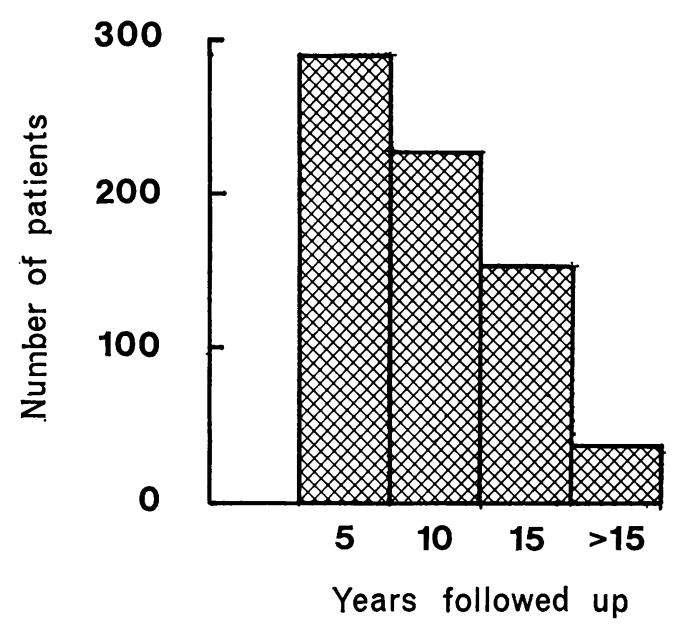

FIG. 4. Analysis of follow up.

Sixty-two patients were therefore unavailable after five years, 26 having died; but of these 16 had received elective surgery either initially or before being 'lost'. One hundred and forty-two patients were followed up for at least 10 years, and 39 for at least 15 years.

SIMPLE CLOSURE ONLY Among the patients treated by simple closure, $84(37.7 \%)$ of the 223 survivors are known to have come to further surgery. One hundred and seventy-eight of these patients were followed up at five years, and by then $43.3 \%$ (77) had proceeded to another operation. At 10 years 58 out of 130 patients $(44.6 \%)$ and at 15 years 19 out of $37(51 \cdot 3 \%)$ had done so (Table II).

SIMPLE CLOSURE WITH GASTROJEJUNOSTOMY The addition of gastrojejunostomy to simple closure appeared to give some protection against further surgery being required. The respective figures for re-operation were, overall two out of $18(11.2 \%)$; for five years two out of $10(20.0 \%)$; and for 10 years two out of six $(33.3 \%)$. No patients in this category were followed up for 15 years (Table II).

PARTIAL GASTRECTOMY None of the 44 patients treated by Polya gastrectomy required further surgery. However, of the six patients with the Billroth I operation, one died postoperatively and two had recurrent ulceration and required conversions to a Polya anastomosis.

FURTHER SURGERY The nature of the second operation employed is given in Table III. Two patients who reperforated were treated by further simple closure initially. For their recurrent symptoms two elderly patients required a gastrojejunostomy. The remaining patients underwent either a partial gastrectomy (76 Polya, one Billroth I) or in those presenting after 1960 a vagotomy and pyloroplasty (seven).

\section{TABLE III}

NATURE OF FURTHER SURGERY

\begin{tabular}{lc} 
Treatment & $\begin{array}{l}\text { Number of } \\
\text { Patients }\end{array}$ \\
\hline Simple closure of second perforation & 2 \\
Gastrojejunostomy only & 2 \\
Billroth I gastrectomy & 1 \\
Polya gastrectomy & 76 \\
Vagotomy and pyloroplasty & 7
\end{tabular}

INDICATIONS FOR FURTHER SURGERY Table IV shows the numbers of patients within each category.

Elective operation Seven patients were operated upon within a few weeks of the initial simple closure because the severity of their preoperative symptoms was considered to merit definitive treatment.

TABLE II

FOLLOW UP OF VARIOUS INITIAL OPERATIONS

\begin{tabular}{|c|c|c|c|c|}
\hline Nature of Initial Operation & Overall & ${ }_{5}^{A t}$ Years & $\begin{array}{l}\text { At } \\
10 \text { Years }\end{array}$ & $\begin{array}{l}\text { At } \\
15 \text { Years }\end{array}$ \\
\hline \multicolumn{5}{|l|}{ Simple closure } \\
\hline No. of patients followed up & 223 & 178 & 130 & 37 \\
\hline No. of patients coming to further surgery & 84 & 77 & 58 & 19 \\
\hline Percentage & $37 \cdot 7$ & $43 \cdot 3$ & $44 \cdot 6$ & $51 \cdot 3$ \\
\hline \multicolumn{5}{|l|}{ Simple closure and gastrojejunostomy } \\
\hline No. of patients followed up & 18 & 10 & 6 & - \\
\hline No. of patients coming to further surgery & 2 & 2 & 2 & - \\
\hline Percentage & $11 \cdot 1$ & 20 & $33 \cdot 3$ & - \\
\hline \multicolumn{5}{|l|}{ Billroth I gast rectomy } \\
\hline No. of patients followed up & 5 & 4 & - & - \\
\hline No. of patients coming to further surgery & 2 & 2 & - & - \\
\hline Percentage & $40 \cdot 0$ & $50 \cdot 0$ & - & - \\
\hline \multicolumn{5}{|l|}{ Polya gastrectomy } \\
\hline No. of patients followed up & 44 & 36 & 15 & 2 \\
\hline No. of patients coming to further surgery & $\mathbf{0}$ & $\mathbf{0}$ & 0 & 0 \\
\hline Percentage & Nil & Nil & Nil & Nil \\
\hline
\end{tabular}


TABLE IV

INDICATIONS FOR FURTHER SURGERY

\begin{tabular}{l} 
Indication \\
\hline Duration of history and severity of \\
symptoms before perforation \\
Recurrent symptoms \\
Further perforation \\
Haemorrhage from ulcer \\
Pyloric stenosis
\end{tabular}

Number of Patients

Recurrent dyspepsia Fifty-three patients came within this group. Recurrent or persistent dyspepsia in a patient with a history of perforation was taken as a strong indication for elective surgery.

Haemorrhage Twelve patients were readmitted because of haemorrhage from the ulcer and were treated by gastrectomy.

Further perforation Ten patients had a further perforation, and in all but two patients an immediate gastrectomy was done.

Pyloric obstruction Pyloric stenosis occurred in six patients and they were treated by gastrectomy.

\section{MORTALITY RATE}

Thirty-five patients died from perforation and this represents a $9.6 \%$ mortality rate (Table V). There

\begin{tabular}{lccc}
\multicolumn{4}{c}{ T ABLE V } \\
MORTALITY RATES \\
& $\begin{array}{l}\text { Number of } \\
\text { Patients }\end{array}$ & $\begin{array}{l}\text { Number of } \\
\text { Deaths }\end{array}$ & $\begin{array}{l}\text { Mortality } \\
\text { Rate (\%) }\end{array}$ \\
\hline $\begin{array}{l}\text { Operative } \\
\text { Simple closure only }\end{array}$ & 312 & 17 & 5.5 \\
Simple closure and & 241 & 13 & 5.4 \\
gastrojejunostomy & 19 & 1 & 5.3 \\
Billroth I gastrectomy & 6 & 1 & 11.9 \\
Polya gastrectomy & 46 & 2 & 3.6 \\
Non-operative & 23 & 18 & 78.4 \\
Totals & 335 & 35 & 9.6
\end{tabular}

were only five survivors from the 23 patients managed without operation although it must be emphasized that the efficacy of conservative treatment cannot be assessed on the basis of this series. The fact that five patients survived is in itself remarkable since all but one had been considered unfit to withstand surgery.

The mortality rate for all operations was $5.5 \%$ (17 out of 312 patients dying) and did not change significantly during the years of the survey (Fig. 3). It compares favourably with recent series which range between $3.5 \%$ and $13.8 \%$ (Amerson, 1957; Hofkin, 1966; Sanders, 1967). Thirteen of 241 patients failed to survive simple closure $(5.4 \%)$ and the addition of gastrojejunostomy did not increase the mortality rate $(5 \cdot 3 \%)$. Billroth I gastrectomy was used in six patients of whom one died from a leaking anastomosis. The mortality of $3.6 \%$ for Polya gastrectomy is significantly lower than the overall operative mortality rate, although of course these patients were selected for their fitness to withstand a major operative procedure.

When mortality is assessed in relation to the ages of the patients treated (Fig. 2), it will be noted that no patients under 40 died. Between the ages of 40 and 70 the mortality rate was between $3.0 \%$ and $3.6 \%$. Over the age of 70 nearly one in four patients died $(23.8 \%)$. In the small number of patients over 80 , one of the 12 died.

\section{RECURRENT PERFORATORS}

Twenty-three $(7 \%)$ patients out of the 330 in the series are known to have had more than one perforation. Two received conservative management of their first perforation and the remainder simple closure only, one patient having had a gastrojejunostomy eight years before his initial perforation.

The second perforation was treated by a Polya gastrectomy in 11 patients, with one death from a leaking anastomosis. One patient had a vagotomy and pyloroplasty. Another had a Billroth I operation which, because of heart failure, he did not survive. Six patients had simple closure of their second perforation. Two did not recover, two proceeded to gastrectomy later, and two were advised to do so but refused. One of these latter patients is well 10 years later, and the other absented himself from the follow-up clinic. A further patient was managed conservatively and came to gastrectomy later.

Six patients died from their second perforation, representing a mortality rate of $26 \%$ which is nearly three times that of a first perforation (9\%). Considering this is a risk to which $7 \%$ of patients with perforation are exposed, it would appear that definitive surgery should be embarked upon without delay in those who, having once perforated, develop further symptoms of active ulceration.

\section{DISCUSSION}

Analysis of the age and sex of the patients in our series has shown them to be a group comparable with others reviewed in recent years. The trend towards an older average age and towards a slight overall decrease in incidence is noted. Efficient follow up of the majority of patients had undoubtedly been aided by improved methods of registration and classification, and its success in providing up-to-date information compares favourably with similar reports.

The results of simple closure, in which $51.3 \%$ of the patients followed up for 15 years and $37.7 \%$ overall came to definitive surgery, are similar to recent reports from other centres. Unfortunately 
TABLE VI

INTERVAL BETWEEN PERFORATION AND FURTHER SURGERY

Indications for Surgery

Years after Perforation

\begin{tabular}{|c|c|c|c|c|c|c|c|c|c|c|c|}
\hline & & & & & & & & & & & \\
\hline & 1 & 2 & 3 & 4 & 5 & 6 & 7 & 8 & 9 : & 10 & $>10$ \\
\hline Recurrent symptoms & 27 & 12 & 5 & 2 & 1 & 3 & 1 & 1 & 0 & 1 & 0 \\
\hline Haemorrhage & 3 & 3 & 2 & 2 & $\mathbf{0}$ & 1 & $\mathbf{0}$ & 0 & 0 & 0 & 1 \\
\hline Further perforation & 2 & 0 & 0 & 3 & 1 & 3 & 1 & 0 & $\mathbf{0}$ & 0 & $\mathbf{0}$ \\
\hline Overall percentage & $42 \cdot 0$ & $60 \cdot 5$ & $70 \cdot 5$ & $79 \cdot 0$ & $81 \cdot 5$ & $90 \cdot 0$ & $92 \cdot 5$ & $94 \cdot 0$ & $96 \cdot 0$ & $99 \cdot 0$ & $100 \cdot 0$ \\
\hline
\end{tabular}

many series do not differentiate between gastric and duodenal ulceration, but Hofkin (1966) and Stabins (1953), who report specifically on duodenal perforations, give figures of $58 \%$ and $36.5 \%$ respectively for patients requiring further surgery.

The improvement in prognosis by the addition of a gastrojejunostomy to the simple closure in older patients is worth noting although the overall figure of only $11.2 \%$ patients coming to further surgery is probably deceptive. The reason suggested for this is that being in an older age range, the numbers surviving for an adequate follow up period is lower than in the other treatment groups. This impression appears to be supported by the fact that of those who do survive 10 years, one third have required a definitive operation.

Billroth I operation was only performed on six patients, but two of them required further surgery. Polya gastrectomy appears to have been satisfactory and no recurrent ulcers have so far been reported.

The majority of patients who came to further surgery did so because of recurrent dyspepsia. It is difficult to compare the indications for this second operation with those in other series, since the readiness with which centres recommend it varies. For instance, in the series of Amerson (1957) over half of the patients came to definitive operation because they developed pyloric obstruction. In fact less than $15 \%$ of his original 247 patients with perforated duodenal ulcer were referred for surgery later, and only three of them for 'intractable pain'. His other referrals were for haemorrhage or further perforation. In other words, most patients only had an operation for a second complication, and persistent dyspepsia alone was seldom treated operatively.

The interval between the initial and second operation varies from series to series and our findings are outlined in Table VI. It will be noted that $42 \%$ of the patients required further surgery within the first year, $81.5 \%$ within five years, and all but one patient within 10 years. These findings are similar to those of Illingworth et al (1946) but contrast with those of Hofkin (1966) who found that over $50 \%$ of his patients came to operation after a delay of longer than five years.
The evolution in management towards elective surgery at the time of perforation is clearly seen, for by 1959 one third of those patients who presented as emergencies were treated in this way. A recent survey of the management of perforated peptic ulcer in Oxford reveals that this change is by no means universal, because between 1957 and 1963 only $3 \%$ of those patients received definitive surgery at the time of perforation (Sanders, 1967).

Despite this trend in our area, there was no increased mortality rate; in fact this was lower in patients who had partial gastrectomy. It has been noted that the years in which more patients were treated definitively were not marked by a significantly increased mortality rate. It would appear therefore that, provided the selection of patients is careful, definitive surgery at the time of perforation carries no increased risk. It has the advantage of saving the patient a prolonged stay in hospital or a second operation. Now that a further evolution in the treatment of duodenal ulcer is being witnessed, and vagotomy and pyloroplasty with its lower mortality rate is the operation of choice, the incentive to its use as the immediate definitive management of the perforation is even greater.

\section{SUMMARY}

Our experience over a 10-year period in the management of perforated duodenal ulcer is outlined. The trend towards immediate definitive surgery without increased mortality is noted. The increased mortality of the second perforation is emphasized, and surgery is advised for those who having once perforated show signs of further ulcer activity.

I wish to express my gratitude to the surgeons of the Royal Berkshire Hospital for allowing me access to their patients, and in particular to Mr Gordon Bohn for his advice and encouragement in the preparation of these papers.

\section{REFERENCES}

Amerson, J. R. (1957). Acute gastroduodenal perforations: a study of 381 patients. Amer. Surg., 23, 735-746.

Cassell, P. G. (1969). The prognosis of the perforated acute duodenal ulcer. Gut, 10, in press. 
Cooley, D. A., Jordan, G. L., Brockman, H. L., and DeBakey, M. E. (1955). Gastrectomy in acute gastroduodenal perforation: analysis of 112 cases. Ann. Surg., 141, 840-852.

Emmett, J. M., and Williams, H. L. (1957). Gastric resection: a definitive treatment for perforated peptic ulcer. Amer. Surg. 23, 993-1000.

Hofkin, G. A. (1966). Course of patients with perforated duodenal ulcers. Amer. J. Surg., 111, 193-196.

Illingworth, C. F. W., Scott, L. D. W., and Jamieson, R. A. (1944). Incidence of perforated peptic ulcer. Brit. med. J., 2, 617-620, 655-658.

Brit. med. J., 1, 787-790
Judin, S. S. (1937). Partial gastrectomy in acute perforated peptic ulcer. Surg. Gynec. Obstet., 64, 63-68.

Mackay, C. (1966). Perforated peptic ulcer in the west of Scotland: a survey of 5,343 cases during 1954-63. Brit. med. J., 1, 701-705.

Sanders, R. (1967). Incidence of perforated duodenal and gastric ulcer in Oxford. Gut, 8, 58-63.

Stabins, S. J. (1953). The aftermath of perforated duodenal ulcer. Surgery, 34, 614-620.

Taylor, H., and Warren, R. P. (1956). Perforated acute and chronic peptic ulcer: conservative treatment. Lancet, 1, 397-399.

Weir, R. D. (1960). Scot. med. J., 5, 257-264. 